\title{
ON THE COMPARATIVE VIRTUES
}

OF DIFTERENT KINDS OF

\section{SARSA PARILLA.}

Bx Mr. JOHN POPE.

COMMUNICATED

Bx Mr. EARLE.

Read Jan. 14, 1823.

THE varied success attendant on the use of sarsaparilla, has been owing, no doubt, to the various qualities of the root itself, and the mode adopted for extracting its virtues; and as long as medical men are in theory divided as to what constitute the active properties of this medicine, and the best methods of obtaining them, so long will its efficacy be partial and unsatisfactory.

A desire to rectify some prevalent errors respecting sarsaparilla, and to establish the relative value of the different kinds, has induced me to devote considerable attention to the subject.

The sarsaparilla imported into the London market is generally distinguished as Lisbon, Honduras, and Vera Cruz, those being the ports from which it has usually been shipped. 
The Lisbon has always been esteemed the best, and commanded the highest price in the market. It is the produce of the Brazilian settlements of Pura and Ataranham in South America, and has acquired the name of Lisbon, from being, till within the last few years, only to be procured at that port. Its characteristics are, externally a reddish or dark brown coat; when cut longitudinally, it has a white farinaceous appearance, and is usually more free from chumps and fibre than the other kinds.

The Honduras is brought from the ports on the bay of that name, Balize, and others adjacent ; and although it has not commanded so good a price as the Lisbon, yet it has, of late years, been held in higher estimation by the medical world, in consequence of its having been brought into notice by some eminent practitioners of the last century. Its characteristics are a dirty brown, sometimes a whitish coat. It is not so red as the Lisbon, is usually more fibrous, and possesses more pith.

The Vera Cruz is mostly brought from that port, and is altogether inferior to the former kinds, being lean, dark, and fibrous. Within the last three or four years, sarsaparilla has been brought from Jamaica, and is generally supposed to be the produce of that island. It differs much from the other kinds in appearance, and still more in the extract it yields. It has a peculiar deep red external coat, is of somewhat close texture, and when cut longi- 
tudinally, that part next the outer coat (which we designate as pith in the other kinds) is found, more or less, to be of a deep red color. It was, some time since, strongly recommended to the medical world by Mr. Richard Battley, whose reputation, as a pharmaceutical chemist, is well known; and who, by a number of very conclusive experiments, satisfactorily established its superiority. $\mathrm{He}$ has very obligingly favored me with the results of his experiments, which, for the most part, fully confirm my own observations. He considers it the growth of Jamaica, and has distinguished it by the term red rete mucosum sarsaparilla, on account of its deep red color, more particularly of the inner bark.

My own inquiries on the subject lead me to conclude, that it is not the growth of that island. As the red is not the only kind brought, by way of Jamaica, into the London market, some parcels which $I$ have examined are undoubtedly the usual Honduras sarsaparilla.

From the best information I have been able to collect, I am decidedly of opinion, that the red sarsaparilla is the umeultioated produce of parts of the Spanish Main, where it is collected by the native or Independent Indians, who barter it in exchange for articles of European commerce to the traders who frequent their shore, and by whom it is carried to Jamaica ; - but the other kinds, more 
particularly the Lisbon, are probably the cultivated produce of the places from whence it is shipped direct to the European market-the great demand for them, being likely to have led to their cultivation, and the pains evidently taken in the trimming, arranging, and packing of the best samples, seems to favour such an opinion.

From a careful and minute examination of all the above kinds of sarsaparilla, it is satisfactorily proved-

That the whole medical efficacy of the plant resides in the bark, and consists of pure extractive matter, of which the best of each kind yields the largest quantity.

That the root deprived of its cortical part, contains only pith, and tasteless woody fibre-yielding nothing but insoluble mucus and a very small proportion of extract either by cold or hot infision.

That the cortical part of sarsaparilla gives out nearly the whole of its virtues by cold infusion in distilled water-very readily to lime-water, or water slightly impregnated with caustic alkali-and that boiling distilled water extracts all its virtues.

That on a comparison of the different kinds of 
sarsaparilla, the red, lately brought from Jamaica, yields by far the largest proportion of extractive matter.

That by submitting the root, cut transversely, to the action of steam or of distilled water, at a temperature somewhat below boiling, an elegant soluble extract may be obtained, containing all the virtues of the plant, not liable to decomposition, and applicable to the various purposes of extemporaneous prescription.

The following is a brief extract, from numerous experiments, which have led to the foregoing conclusions.

Equal quantities, by weight, of the several sorts of sarsaparilla, by infusion of the split root in distilled water, and the solutions filtered through paper, gave hard extract in the following proportions :-

$\begin{array}{lccc} & \begin{array}{c}\text { By cold } \\ \text { infusion. }\end{array} & \begin{array}{c}\text { Subsequently } \\ \text { by hot } \\ \text { infusion. }\end{array} & \text { Total. } \\ \text { Red Rete Mucosum * (Jamaica) } & 4.4 & 20 & 64 \\ \text { Lisbon, fine picked sample } & 28 & 14 & \mathbf{4 2}\end{array}$

* Mr. Battley's experiments were still more in favour of the red in comparison of the other kinds, about 3 to 1 . The unusually fine quality of the Lisbon and Honduras which I employed, may, in some measure, explain the difference. 
Lisbon, second quality* By cold. Subsequently
by hot
infusion. Total. $\begin{array}{llll}\text { Honduras, fine picked sample } & 30 & 18 & 48\end{array}$ Do. second quality * $21 \quad 14 \quad 36$

Equal quantities of the cortical part, and of the rood carefully separated, gave, by infusion in boiling distilled water, after filtration, the following proportions of hard extract :-

Bark of the Red Jamaica - - $\quad 100$ Wood of do. $\quad$ - $\quad$ - $\quad$ - $\quad$ - 20

Bark of the Honduras (the fine sample) - 48 Wood do. do. - 24

The root sliced, bruised, boiled, and expressed in the usual way gave extract as follows :-

Red

Lisbon $130\left\{\begin{array}{c}\text { or very little more than obtain- } \\ \text { ed by infusion. }\end{array}\right.$ Honduras 180 nearly double the quantity obtained by infusion, but a very tough insoluble extract, containing all the mucilaginous part of the plant, consequently extremely prone to spontaneous decomposition.

* The second sort employed was of good average quality, such as is usually kept for sale. 
From the above few parts thus briefly stated, it is evident, that by the usual mode of treating sarsaparilla, is chiefly obtained a large proportion of insoluble, inefficacious matter: that the kinds of root usually selected, contain only a small proportion of the active properties of the plant, compared with that lately brought from Jamaica, and which is decidedly the best we are at present acquainted with.

96, Oxford Street. 